\title{
Endolithic Bacterial Diversity in Lichen-Dominated Communities Is Shaped by Sun Exposure in McMurdo Dry Valleys, Antarctica
}

\author{
Ambra Mezzasoma $^{1} \cdot$ Claudia Coleine $^{2} \cdot$ Ciro Sannino $^{1}\left[\right.$ Laura Selbmann $^{2,3}$
}

Received: 2 February 2021 / Accepted: 5 May 2021 / Published online: 3 June 2021

(c) The Author(s) 2021

\begin{abstract}
The diversity and composition of endolithic bacterial diversity of several locations in McMurdo Dry Valleys (Continental Antarctica) were explored using amplicon sequencing, targeting the V3 and V4 of the 16S region. Despite the increasing interest in edaphic factors that drive bacterial community composition in Antarctic rocky communities, few researchers focused attention on the direct effects of sun exposure on bacterial diversity; we herein reported significant differences in the northern and southern communities. The analysis of $\beta$-diversity showed significant differences among sampled localities. For instance, the most abundant genera found in the north-exposed rocks were Rhodococcus and Blastococcus in Knobhead Mt.; Ktedonobacter and Cyanobacteria Family I Group I in Finger Mt.; Rhodococcus and Endobacter in University Valley; and Segetibacter and Tetrasphaera in Siegfried Peak samples. In south-exposed rocks, instead, the most abundant genera were Escherichia/Shigella and Streptococcus in Knobhead Mt.; Ktedonobacter and Rhodococcus in Finger Mt.; Ktedonobacter and Roseomonas in University Valley; and Blastocatella, Cyanobacteria Family I Group I and Segetibacter in Siegfried Peak. Significant biomarkers, detected by the Linear discriminant analysis Effect Size, were also found among north- and south-exposed communities. Besides, the large number of positive significant co-occurrences may suggest a crucial role of positive associations over competitions under the harsher conditions where these rock-inhabiting microorganisms spread. Although the effect of geographic distances in these extreme environments play a significant role in shaping biodiversity, the study of an edaphic factor, such as solar exposure, adds an important contribution to the mosaic of microbial biodiversity of Antarctic bacterial cryptoendolithic communities.
\end{abstract}

Keywords Antarctic cryptoendolithic communities · Bacteria · Southern Victoria Land · Sun exposure · Extreme environments

\section{Introduction}

The McMurdo Dry Valleys (MDV; Southern Victoria Land, Continental Antarctica) represents one of the most remote, driest and coldest environments on Earth. This region is the largest ice-free area in Antarctica [1], characterised by low temperatures, limited snowfalls, high UV radiation

Ciro Sannino

ciro.sannino@unipg.it

1 Department of Agricultural, Food and Environmental Sciences, University of Perugia, Borgo XX Giugno 74, 06121 Perugia, Italy

2 Department of Ecological and Biological Sciences, University of Tuscia, Viterbo, Italy

3 Italian Antarctic National Museum (MNA), Mycological Section, Genoa, Italy and strong katabatic winds. The icy coverage is limited to glaciers and ice-covered lakes, while rocky ice-free mountains and desiccate valleys dominate the landscape. There, the naked rocks supply the main habitat for microbial life [2], hosting the highest standing biomass in this area [3, 4]. Indeed, environmental conditions are so harsh as to be almost incompatible with active life, and microbes can mainly find a refuge dwelling inside rock porosity, forming the so-called endolithic communities, which represent the main and often the sole life-forms in these areas [5].

In these habitats, temperature fluctuations and the thermal inertia of rocks may only occasionally create a transient wetting layer. However, the micro-architectural structure of porous rocks acts as a sponge, prolonging water availability within rock microhabitats which may support the metabolic activity of the endolithic communities in the narrow seasonal window (below $1000 \mathrm{~h}$ per year) [6]. Among the different 
types of endolithic colonisation, the most widespread and known are the cryptoendolithic communities dominated by lichens, colonising quarzitic sandstone as a preferential substratum for its homogeneous porosity and high translucence [7]. These communities are typically organised in a coloured, and biologically distinct, stratification in a depth of about $10 \mathrm{~mm}$ below rock surface, according to the physiological requirements of each microbial compartment. Nonlichenised Chlorophyte algae and Cyanobacteria occur in the deepest green band, where harmful solar radiation is more efficiently screened; immediately above, in the white band, lichenised fungi, in obligate symbiosis with algae act, together with phototrophs in the green band, as primary producers, while other fungi and bacteria play a role as consumers $[8,9]$.

A notable deal of efforts has been recently paid to untangle which environmental (and biological) factors that can putatively drive the composition of Antarctic cryptoendolithic communities or whether environmental factors can diversify highly specialised microbial communities in soils and frozen lakes in the same area of Antarctica [10,11]. Lee et al. [12] suggested that latitude, $\mathrm{pH}$, nitrate and sulphate concentrations are significantly correlated with the dominant phyla found in rock-inhabiting bacterial communities of several locations in Victoria Land and that rock-inhabiting bacterial communities predominantly consisted of either Actinobacteria or Proteobacteria. Recently, sun exposure was proved to affect Antarctic cryptoendolithic fungal diversity; indeed, more direct sun-exposed rock surfaces (northern exposed rocks) can maintain heating for much longer time due to the thermal inertia of rocks, while microbes may take advantage in terms of water availability (due to ice or snow melting). Both higher temperature and water availability promote metabolic activities with a consequent effect on biodiversity $[5,13,14]$. However, the effect of sun exposure as an environmental factor shaping local community structure and co-occurrence patterns has still never been investigated in Bacteria.

In this work, we aimed (i) to assess rock-inhabiting bacterial communities in the Dry Valleys; (ii) identify marker taxa and estimate the co-occurrences among taxonomicallyrelated bacterial taxa; and (iii) to clarify whether the different exposure (i.e. north vs. south) shapes cryptoendolithic bacterial communities.

\section{Methods}

\section{Study Area}

The area of study was in MDV, Southern Victoria Land (Continental Antarctica), an ice-free area where the landscape is characterised by huge sandstone outcrop formations of the Beacon Supergroup, of the same geological origin, dating back to the Devonian-Triassic (400 to 250 MYA), with quite homogeneous chemical composition and texture, constituted mostly of orthoquartzite $[15,16]$. Sandstone samples were collected during the XXXI Italian Antarctic Expedition (Dec. 2015-Jan. 2016) from four localities (Table 1; Fig. 1; and Supplementary Fig. 1)): (i) Siegfried Peak (SP, number of samples, $n=12$ ) is located at the east side of Odin Valley in the Asgard Range of Victoria Land; (ii) Finger Mountain (FM, $n=11$ ) is located on the north side of Turnabout Valley, in the group of Quartermain Mountains; (iii) University Valley (UV, $n=9$ ) is one of four small valleys in the Quartermain Mountains); (iv) Knobhead (KM, $n=8$ ) is an ice-free mountain, standing south of the western end of Kukri Hills and overlooking the Ferrar and Taylor Glaciers. All these sites were located in the Stable Upland Zone (SUZ) microclimatic area, in which the harshest climatic conditions for microbial life occur [17].

Both north- and south-exposed rocky surfaces have been collected to highlight the effect of opposite sun exposure on the bacterial assemblages. Conditions for northern-exposed surfaces are, in fact, considerably more favourable than southern-facing rocks that are much cooler, being almost permanently in the shadow $[18,19]$.

The presence of lithic colonisation was first assessed by direct observation in situ using a magnifying lens. Rock samples, colonised by endolithic lichen-dominated microbial
Table 1 Characteristics of sampling sites: altitude, relative humidity (measured during the sampling), $\mathrm{pH}$ and geographic coordinates (modified by Coleine et al., 2020 [13])

\begin{tabular}{lllll}
\hline Site & $\begin{array}{l}\text { Altitude }(\mathrm{m} \\
\text { a.s.l. })\end{array}$ & $\begin{array}{l}\text { Relative } \\
\text { humidity (\%) }\end{array}$ & $\mathrm{pH}$ & Coordinates \\
\hline Finger Mt. North & 1720 & 35 & $5.58 \pm 0.01$ & $7^{\circ} 45^{\prime} 0.9^{\prime \prime} \mathrm{S}, 160^{\circ} 44^{\prime} 44.5^{\prime \prime} \mathrm{E}$ \\
Finger Mt. South & 1720 & 35 & $5.54 \pm 0.01$ & $77^{\circ} 45^{\prime} 10.3^{\prime \prime} \mathrm{S}, 160^{\circ} 44^{\prime} 40.3^{\prime \prime} \mathrm{E}$ \\
Knobhead North & 2150 & 50 & $4.83 \pm 0.01$ & $77^{\circ} 54^{\prime} 37.8^{\prime \prime} \mathrm{S}, 161^{\circ} 34^{\prime} 48.8^{\prime \prime} \mathrm{E}$ \\
Knobhead South & 2150 & 38 & $4.76 \pm 0.02$ & $77^{\circ} 54^{\prime} 43.6^{\prime \prime} \mathrm{S}, 161^{\circ} 34^{\prime} 39.3^{\prime \prime} \mathrm{E}$ \\
Siegfried peak North & 1620 & 52 & $6.11 \pm 0.03$ & $77^{\circ} 34^{\prime} 43.3^{\prime \prime} \mathrm{S}, 161^{\circ} 47^{\prime} 11.7^{\prime \prime} \mathrm{E}$ \\
Siegfried peak South & 1620 & 54 & $6.22 \pm 0.03$ & $77^{\circ} 34^{\prime} 39.9^{\prime \prime} \mathrm{S}, 161^{\circ} 47^{\prime} 17.4^{\prime \prime} \mathrm{E}$ \\
University Valley North & 2090 & 18 & $4.57 \pm 0.00$ & $77^{\circ} 52^{\prime} 27.6^{\prime \prime} \mathrm{S}, 160^{\circ} 44^{\prime} 38.9^{\prime \prime} \mathrm{E}$ \\
University Valley North & 2200 & 39 & $4.69 \pm 0.05$ & $77^{\circ} 52^{\prime} 21.6^{\prime \prime} \mathrm{S}, 160^{\circ} 45^{\prime} 20.5^{\prime \prime} \mathrm{E}$ \\
\hline
\end{tabular}




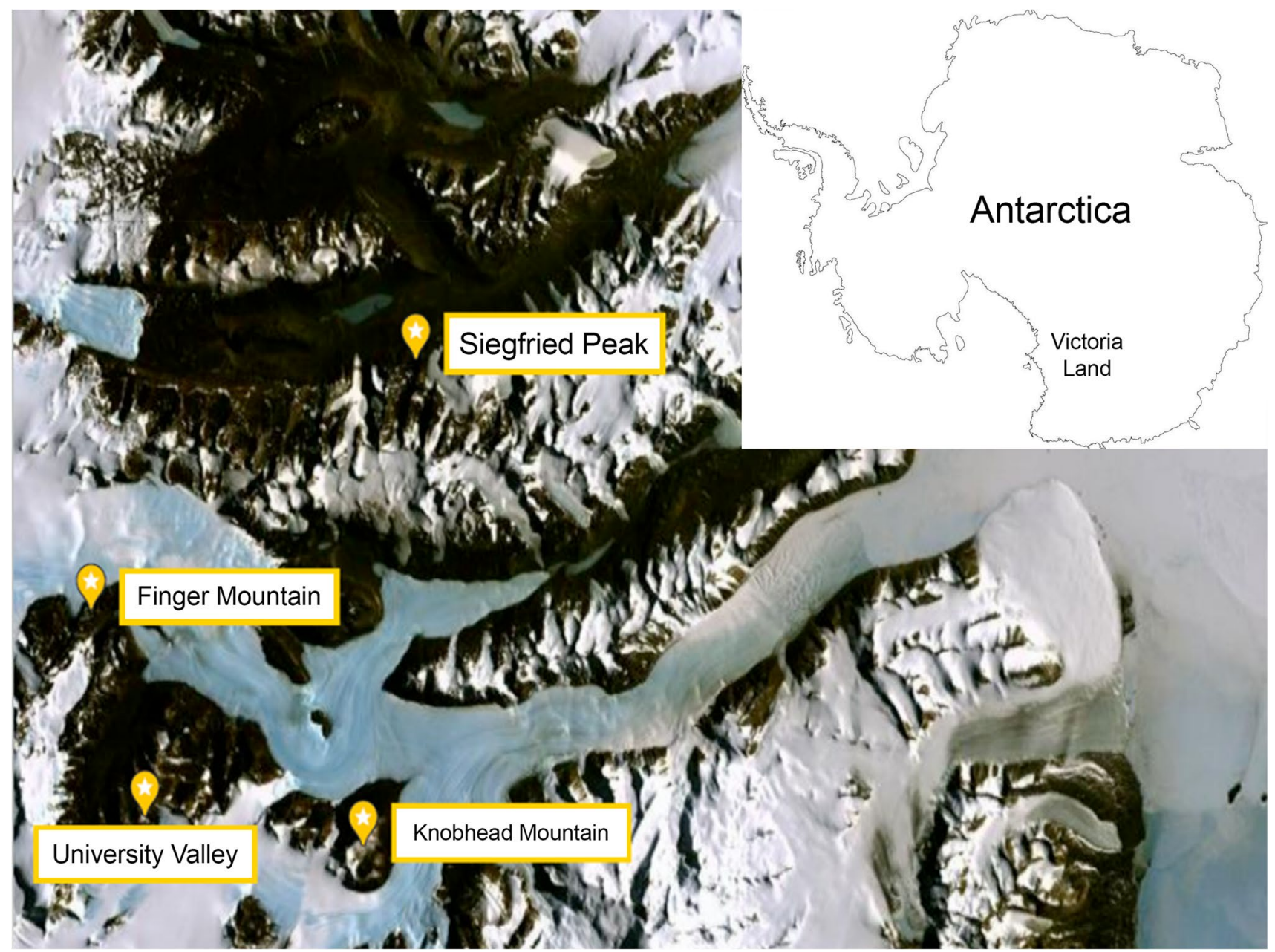

Fig. 1 Map of the study area showing the location of sampling sites

communities, have been collected using a geological hammer and sterile chisel and placed in sterile bags, and then transported and stored at $-20{ }^{\circ} \mathrm{C}$ in the Italian National Antarctic Museum-Culture Collection of Fungi from Extreme Environments (MNA-CCFEE). An aliquot of each sample has been shipped to the University of Perugia, Italy, for microbiological analysis. Another aliquot of each sample was used to determine $\mathrm{pH}$ ( $\mathrm{pH}$ meter Hanna Instruments) using oven-dried rock samples and a rock:water ratio of $1: 1$ [20].

\section{DNA Extraction and Metabarcoding Sequencing}

Total DNA was extracted from $0.25 \mathrm{~g}$ of crushed rocks using Power Soil DNA Isolation Kit (Qiagen, Germany) following the manufacturer's instructions and then quantified using QuBit 2.0 Fluorometer Assay (Life Technologies Corporation). The V3 and V4 regions of the $16 \mathrm{~S}$ rRNA gene were amplified using the barcoded primers
Pro341F: 5'-CCTACGGGNBGCASCAG-3' and Pro805R: Rev 5'-GACTACNVGGGTATCTAATCC-3' [21]. PCR solutions and thermocycling conditions were carried out as reported in Coleine et al. [13]. PCR products were then barcoded and pooled. Amplicon sequencing was performed on the Illumina MiSeq platform $(2 \times 300$ bp reads $)$ by BMR Genomics (Padua, Italy).

The 16S dataset was processed by AMPtk (Amplicon ToolKit for NGS) v 1.0.0. [22]. Briefly, reads were demultiplexed and trimmed, and chimeras were removed. Low-quality reads (dropping reads less than $100 \mathrm{bp}$ ) and those shorter than $250 \mathrm{bp}$ have been removed and excluded by downstream analysis. The $16 \mathrm{~S}$ sequences were clustered with VSEARCH v 2.3.2 algorithm [23] using a 97\% percent identity parameter to generate the Operational Taxonomic Units (OTUs). Singletons and rare OTUs $(<5$ reads across the whole dataset) were additionally removed. Taxonomy was assigned using the hybrid SINTAX/UTAX database [24]. Sequences were submitted to the European 
Nucleotide Archive (EMBL - EBI) under accession number PRJEB39480.

\section{Downstream analysis}

Shared OTUs and unique OTUs among north and south exposure in each locality were visualised by Venn diagrams. Venn diagrams were plotted using the R packages 'gplots', 'VennDiagram' and 'eulerr' [25-27]. Stacked bar plots at the phylum and genus ranks were obtained using relative abundance. Considering the genus rank, all taxa, which showed relative abundance lower than $2 \%$, were clustered into a taxonomic group named 'Others'. For each northand south-exposed surface, alpha diversity metrics, species richness (S), Shannon's index (H') and Simpson's index of dominance (1-D), were calculated. Pairwise comparisons of biodiversity indices among north- and south-exposed rocks were performed by Student's test, after ANOVA analysis $(p<0.05)$. To explore diversity among localities, beta-diversity analysis was performed using a Bray-Curtis distance matrix and the results were visualised by PCoA plot. The effect of sampling site (locality) on the bacterial community structure was assessed by conducting a permutational ANOVA (PERMANOVA, number of permutations =9999) with the function 'adonis' implemented in the vegan package v. 2.5.5 [28]. Moreover, after transforming the OTU table (square root transformation), Bray-Curtis distance matrices were plotted to show ordinal distances among northern and southern samples in each sampling site with a non-metric multidimensional scaling (NMDS) analysis.

Linear discriminant analysis Effect Size (LEfSe) algorithm (LDA score $\geq 2 ; p$ value $<0.05$; strategy for multi-class analysis 'all-against-all') has been implemented to identify the biomarkers (bacterial taxa) associated with each sun exposure, using the Galaxy web interface (https://hutte nhower.sph.harvard.edu/galaxy/) [29].

Heatmaps reporting co-occurrences among bacterial phyla were implemented using the Pearson correlation coefficient $(p<0.05)$. R packages 'lsr', 'Hmisc' and 'corrplot' were used for computing correlation matrix and graphical display [30].

\section{Results}

\section{Characterisation of Bacterial Diversity}

After removing OTUs assigned to chloroplasts and Archaea, a total of 893,608 reads have been clustered in 560 OTUs. Venn diagrams reported that all localities shared more than $50 \%$ of OTUs, except for samples collected from KM that showed the highest number of unique OTUs in the northernexposed surface (Supplementary Fig. 2).
The most abundant phyla found in north-exposed rocks were Actinobacteria $(68.44,43.28 \%)$ and Proteobacteria $(15.42,31.56 \%)$ in KM and UV, respectively, Chloroflexi (46.6\%) and Cyanobacteria (25.97\%) in FM and Actinobacteria $(25.82 \%)$ and Bacteroides $(42.71 \%)$ in SP. On the other hand, in the south-exposed ones, Proteobacteria (73.7\%) and Firmicutes (13.09\%) were the most abundant phyla in KM, Chloroflexi (30.32\%) and Actinobacteria (20.72\%) in FM, Actinobacteria (37.23\%), Bacteroides (25.37\%) and Proteobacteria (23.2\%) in UV, Cyanobacteria (43.51\%) and Acidobacteria (22.4\%) in SP (Fig. 2).

More than 200 genera were found in the examined rocks. Blastocatella, Blastococcus, Ktedonobacter, Roseomonas, Rhodococcus, Segetibacter and Tetrasphaera showed a relative abundance higher than $1 \%$ at least in two samples. Unclassified OTUs at the genus level were found in all sites, and their abundance amounts to $34 \%$ of the total. Overall, the south-exposed samples reported a higher number of unclassified OTUs at genus level than the north ones (Fig. 3).

The most abundant genera found in north-exposed rocks were Rhodococcus $(56.3 \%)$ and Blastococcus $(5.54 \%)$ in KM, Ktedonobacter (42.75\%) and Cyanobacteria Family I GpI (10.2\%) in FM, Rhodococcus (29.6\%) and Endobacter (9.96\%) in UV and Segetibacter (11.03\%) and Tetrasphaera (8.33\%) in SP sample. Regarding south-exposed rocks, the most abundant genera were as follows: Escherichia/Shigella (48.68\%) and Streptococcus (2.96\%) in KM, Ktedonobacter (27.83\%) and Rhodococcus (15.80\%) in FM, Ktedonobacter (25.30\%) and Roseomonas (7\%) in UV and Blastocatella (7.9\%), Cyanobacteria Family I GpI (7.31\%) and Segetibac$\operatorname{ter}(7.42 \%)$ in SP.

\section{Effects of Sun Exposure on Biodiversity and Community Composition}

Considering the different exposure in the studied localities, only SP showed a significant difference $(p<0.05)$ between north- and south-exposed rocks in species richness (Supplementary Table 1). Shannon's index (H') and Simpson index (1-D) did not show any significant differences (Student's Test, $p>0.05$ ) between north- and south-exposed samples in each locality.

Dissimilarity in community composition showed significant differences $(p<0.05)$ among the four localities studied (Fig. 4). Likewise, north- and south-exposed rocks showed significant differences in community composition in FM $(p=0.0018)$, in KM $(p=0.0179)$ and in SP $(p=0.0109)$. No significant differences $(p=0.301)$ were detected for UV samples (Fig. 5).

The LEfSe analysis showed differences among differently exposed rocks in FM, as follows: Ktedonobacter, Cyanobacteria Family I Group I, Sphingobacterium, Roseomonas and 


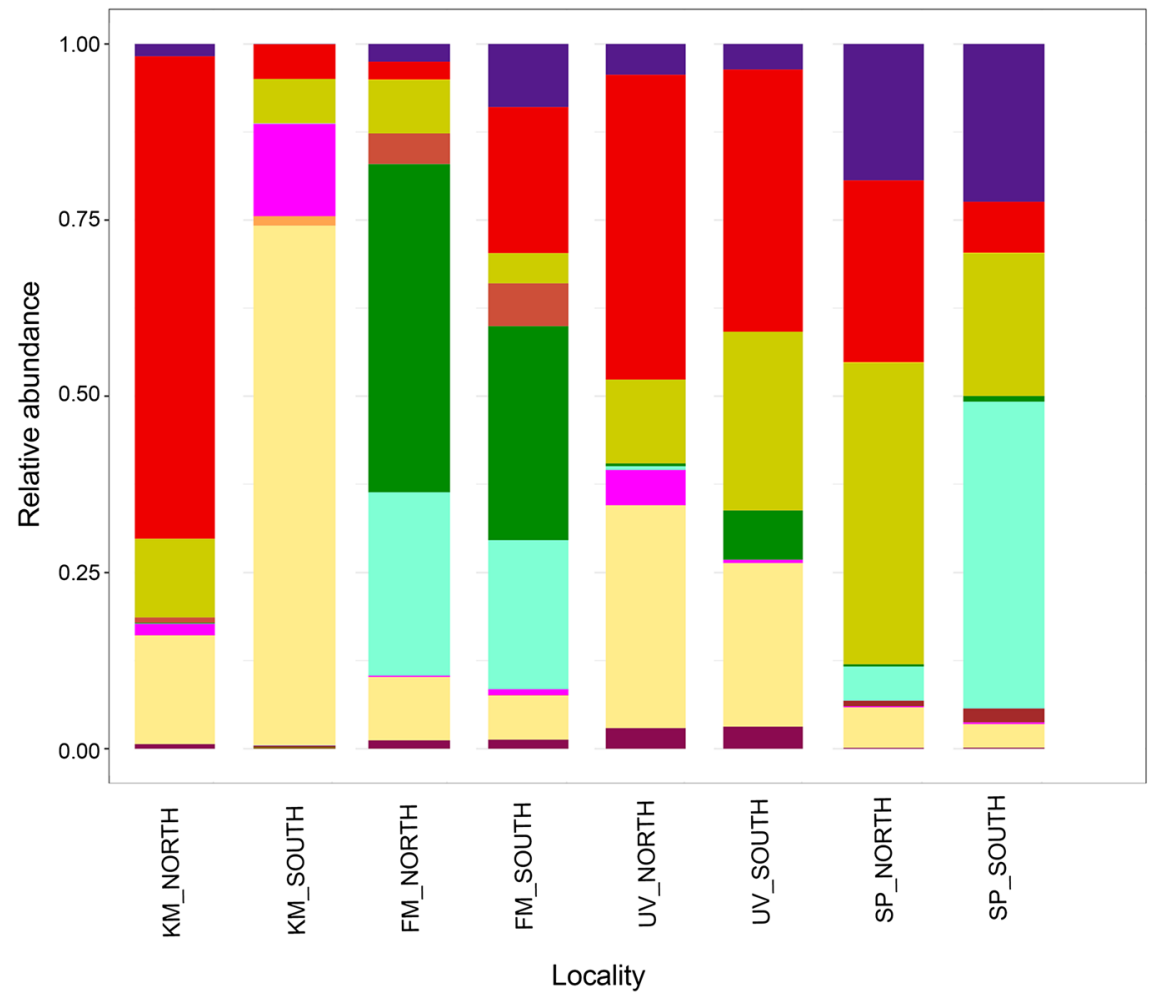

\begin{tabular}{l} 
Phyla \\
Acidobacteria \\
Actinobacteria \\
Armatimonadetes \\
Bacteroidetes \\
candidate_division_WPS-2 \\
Candidatus_Saccharibacteria \\
Chloroflexi \\
Cyanobacteria \\
Deinococcus-Thermus \\
\hline Fibrobacteres \\
\hline Firmicutes \\
Fusobacteria \\
Gemmatimonadetes \\
Planctomycetes \\
Proteobacteria \\
Tenericutes \\
Unclassified \\
\hline Verrucomicrobia
\end{tabular}

Fig. 2 Relative abundances of the dominant bacterial phyla in the cryptoendolithic communities in Victoria Land, Antarctica

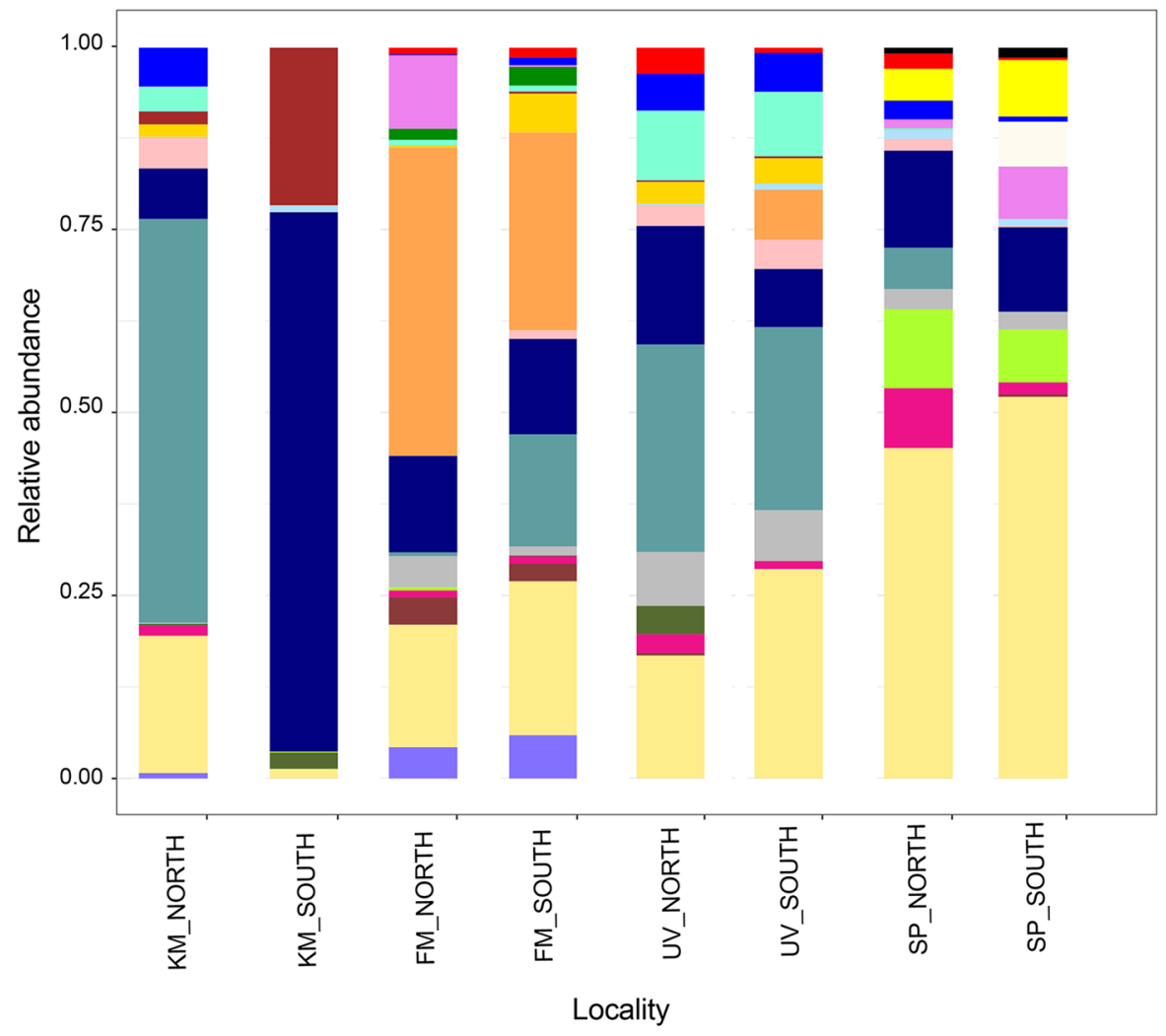

Genera
Acidobacteria_Gp4
Bauldia
Blastocatella
Blastococcus
Chitinophaga
Cyanobacteria_Gpl
Cyanobacteria_GplX
Endobacter
Escherichia/Shigella
Granulicella
Hymenobacter
Ktedonobacter
Nakamurella
Others
Rhodococcus
Roseomonas
Segetibacter
Streptococcus
Tetrasphaera
Thermosporothrix
Unclassified
WPS-2_genera_incertae_sedis

Fig. 3 Relative abundances of the dominant bacterial genera (abundance $>1 \%$ in two localities) in the cryptoendolithic communities in Victoria Land, Antarctica 


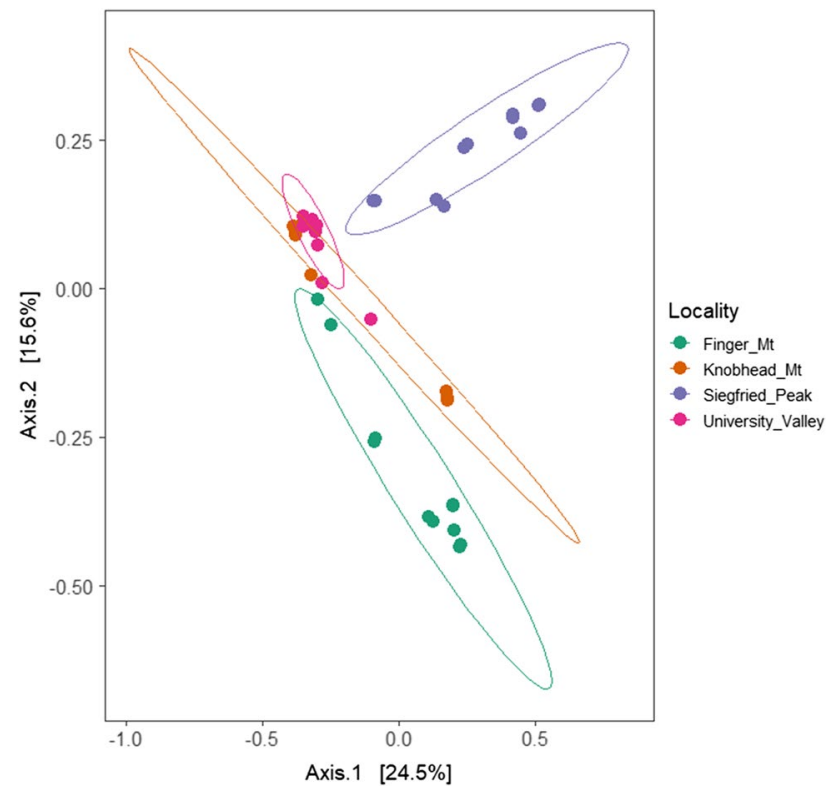

Fig. 4 Principal coordinates analysis based on Bray-Curtis distance matrix and calculated using all bacterial OTUs. The effect of sampling site (locality) on bacterial community structure was assessed by conducting a permutational ANOVA (PERMANOVA, number of permutations $=9,999)$. $p$ value $=0.001$

Mucilaginibacter at the genus level and Acetobacteraceae and Chitinophagaceae at family level for north-exposed rocks; instead, in south-exposed rocks of FM, the relevant biomarkers belonged to Rhodococcus, Ktedonobacter, Granulicella and Nakamurella genera, Nocardiaceae and Enterobacteriaceae at the family level, to Actinobacteria at phylum and class level. In north-exposed rocks of SP, the relevant taxa were Actinobacteria at the phylum level, Nocardiaceae, Intrasporangiaceae and Nakamurellaceae at family rank and Tetrasphaera, Rhodococcus and Nakamurella for genus level; on the contrary, Cyanobacteria were the most important biomarker in SP south-exposed samples. Bacteroidetes phylum and its class, Sphingobacteria, together with Alphaproteobacteria class, showed the highest LDA score in north-exposed samples collected in $\mathrm{KN}$; differently, the classes Bacilli, Gammaproteobacteria and Betaproteobacteria, and the genus Propionibacterium were the discriminating taxa in southern surfaces. Finally, at UV, the north- and south-exposed rocks differ at genus level: Endobacter and Ehrlichia characterised the north exposure, whereas Desulfotomaculum and Acidovorax were present in the south (Supplementary Figs. 3, 4 and 5).

A total of 21 positive pairwise significant $(p<0.05)$ correlations were found among OTU abundances assigned to phylum level: Gemmatimonadetes vs. candidate division WPS-2 $(r=0.99)$; Planctomycetes vs. Cyanobacteria $(r=0.99)$ and Deinococcus Thermus vs. Acidobacteria
Fig. 5 Non-metric NMDS and PERMANOVA analysis of sequences from North- and South-facing rocks, based on square root-transformed abundance data. Compositional dissimilarity was calculated using Bray-Curtis distance, and ellipses plotted using multivariate normal distribution at a confidence level of $95 \%$

$(r=0.95)$ showed the highest value by Pearson correlation (Fig. 6; Supplementary Table 2).

\section{Discussion}

The effect of sun exposure on bacterial assemblages in the lichen-dominated communities, dwelling inside Antarctic rocks, collected from four sites of MDV (accounted as the closest Martian analogue on Earth) was explored. North- and south-exposed rocks were considered to highlight the effect of the different environmental pressures due to opposite sun exposure. These microorganisms live close to the limit of their tolerance, and the change in sun exposure may critically affect the conditions for life [31].

Actinobacteria was the most abundant phylum and almost all the representative OTUs, belonging to this phylum, were assigned to Blastococcus and Tetrasphaera. Both genera were rarely found in Antarctica, although Pudasaini et al. [32] hypothesised that the low frequency of isolation of the genus Blastococcus and other endemic genera in Antarctica could be related to methodological issues in culturedependent approach. Crits-Christoph et al. [33] performed metagenomic analyses of bacterial communities from two rock substrates (calcite and ignimbrite) in the Atacama Desert and revealed that Bacteroidetes were represented by Segetibacter in the ignimbrite microbial community. This genus occurred in SP and KM south sites, suggesting the peculiar adaptation of this genus to extreme habitats. Finally, the genus Roseomonas was the most representative taxon for the phylum Proteobacteria, and the reads assigned to this genus were uniformly distributed over all the analysed locations. In previous studies concerning Antarctic environments, this genus was recovered in Antarctic Dry Valleys soils, in the perennially ice-covered Lake Untersee, and a water column of freshwater Lake Radok [34-37], confirming the cosmopolitan aptitude of this genus.

Species richness exhibited a significant difference $(p<0.05)$ between north- and south-exposed rocks only in Siegfried Peak site. Besides, it might be considered that the south-exposed surfaces in this locality were positioned in a depression of the rock surface creating a protective niche that allowed the development of epilithic lichens to a certain extent (Supplementary Fig. 1h ). The more favourable conditions may have led to the higher diversification found 

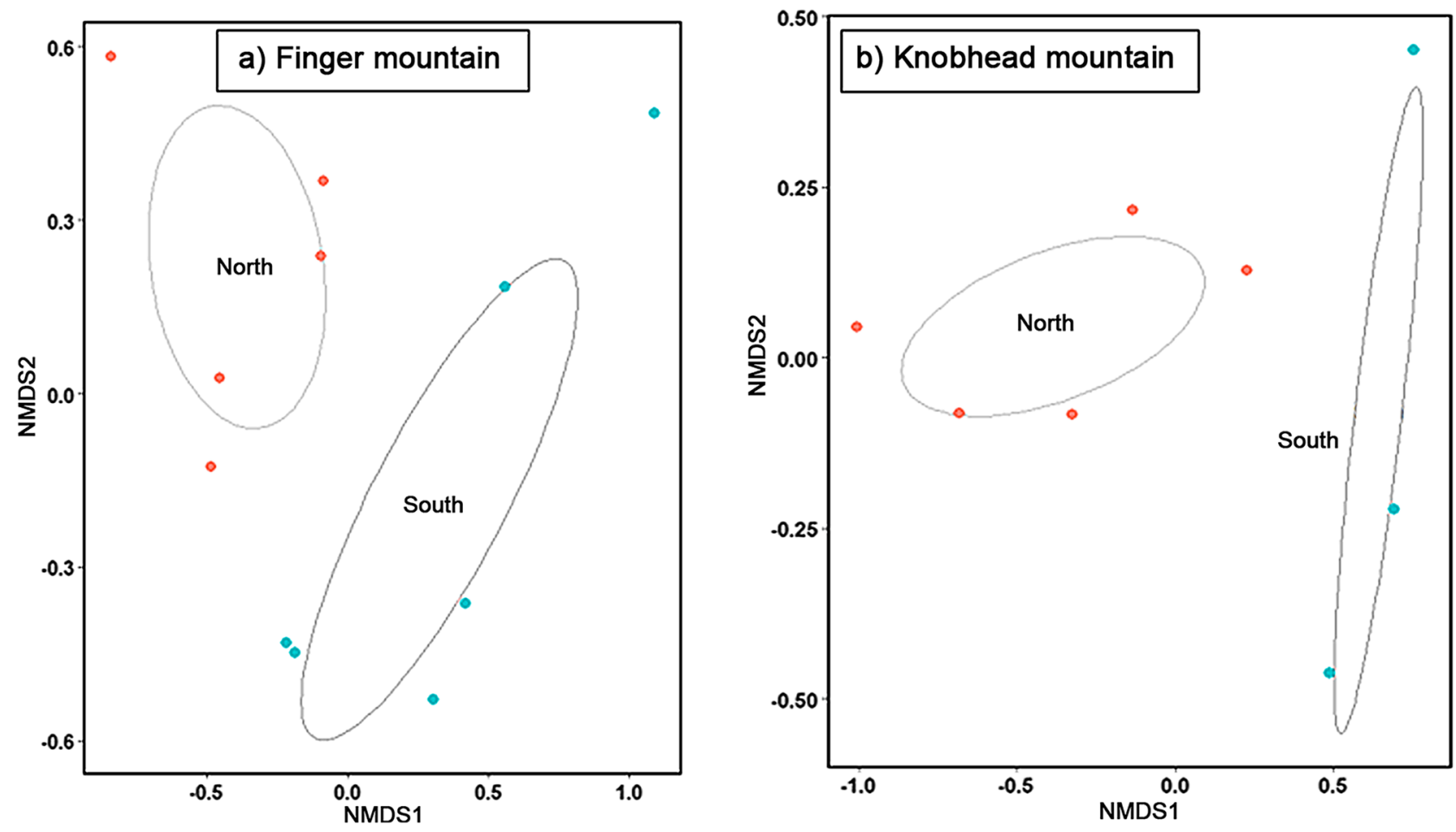

$\mathrm{p}$ value $=0,0018$

$p$ value $=0,0179$

$F$ value $=3,357$

NMDS stress $=0,118$

$F$ value $=5,904$

NMDS stress $=0,03$
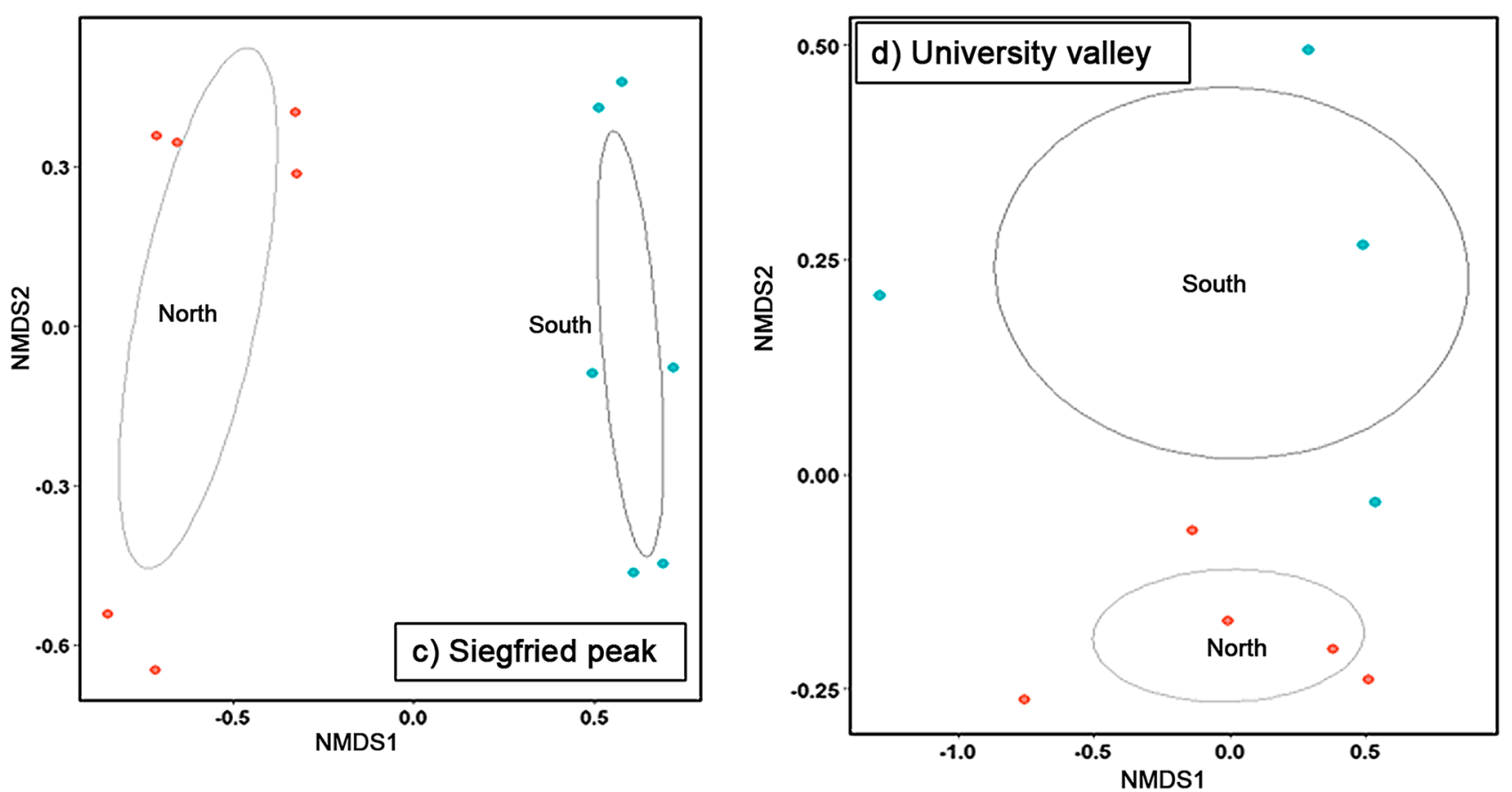

$p$ value $=0,0109$

$F$ value $=3,697$

NMDS stress $=0,0689$

$p$ value $=0,301$

$F$ value $=1,142$

NMDS stress $=0,06$ 
Fig. 6 Heatmap summarising pairwise significant $(p<0.05)$ correlations among bacterial OTUs occurring in ice-free rocks under study (McMurdo Dry Valleys, Antarctica). The color key for the correlation values is shown on the right of the figure. The analysis was performed considering the OTUs classified at phylum level by Pearson coefficient (relative abundance data $>1 \%$ )

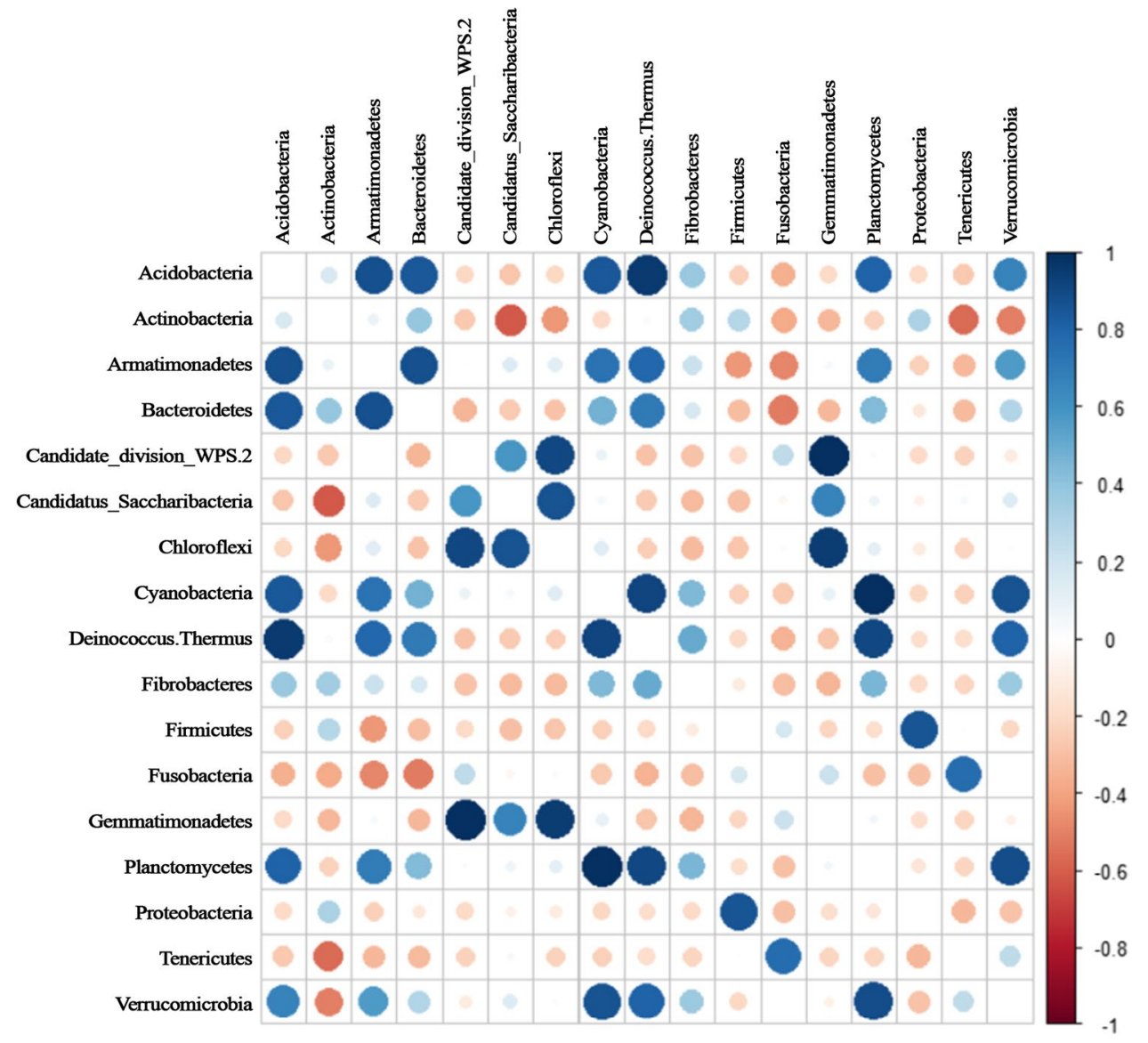

compared not only to north-exposed surfaces but also to all other analysed locations.

Results of beta-diversity reported significant differences among the studied sites. The factor 'habitat' (sampled localities) accounted for $35 \%$ of the total community variation among samples. Siegfried Peak, located in a more distant position compared to the others, falls apart in the diagram, denoting that biodiversity is related to geographic distance, particularly in these remote and inhospitable environments where the spreading and successful settlement of bacterial cells is a challenge, promoting the evolution of local populations.

North- and south-exposed rocks showed significant differences in community composition $(p<0.05)$, except for University Valley. These data proved that sun exposure significantly influences and shapes the biodiversity of bacterial communities. Besides, the geochemically quite homogeneity of rock between north- and south-exposed samples, the same area of sampling (MDV) and the comparable altitudes [15, 16] can make other environmental factors to be considered negligible.

By LEfSe analysis, the relative abundance of Rhodococcus and Ktedonobacter genera were significantly different between the north- and south-exposed samples in SP and
FM and, therefore, can be considered biomarkers of these two conditions. The genus Rhodococcus includes the most common species recorded from Antarctic environments [38, 39]. Members of this genus can grow in a broad range of temperatures, below $0{ }^{\circ} \mathrm{C}$ up to $50{ }^{\circ} \mathrm{C}$ [40]. The adaption to cold was also demonstrated by Goordial et al. [41] that isolated from Antarctic Dry Valley permafrost, Rhodococcus sp. JG-3, capable of growth from 30 down to $-5^{\circ} \mathrm{C}$. Several studies, moreover, focused attention on the abilities of some Rhodococcus strains to degrade phenols and hydrocarbons in contaminated soils in Antarctica [42, 43]. The genus Rhodococcus and even sequences assigned to the family Nocardiaceae, to which it belongs, were widespread, being found almost in all sites. The uncultured genus Ktedonobacter was found with high relative abundance $(>10 \%)$ but at FM only. High relative abundances of Ktedonobacteria are commonly found in extreme environments $[44,45]$. However, the enormous variety of environmental conditions (high and low temperatures, nutrient-rich and oligotrophic substrates, high and low $\mathrm{pH}$ ), where Ktedonobacteria class can thrive, suggests that these Gram-positive, aerobic and mycelia-forming actinomycetes-like bacteria could be able to produce secondary metabolites, to survive in extremely different conditions and different geochemical rock surfaces $[46,47]$. In 
all samples, few reads were assigned to Thermosporothrix, which belonged to Ktedonobacteria. This finding suggests setting further culturable conditions to isolate new strains in this genus because, to the best of our knowledge, only thermophilic strains can be successfully cultivated [48].

Among the most representative members of these communities, some phyla have already been found in other previous works [9, 49], but focusing attention on sun exposure and different sampling sites, some poorly studied microorganisms and their unexplored interactions emerged. For instance, Gemmatimonadetes are frequently detected in soils and their relative abundance in 16S rRNA gene libraries (>500 sequences) is from 0.2 to 6.5\% [50]. In Antarctica, their relative abundance was even higher in a pyrosequencing investigation (15\%) of lithobionts and soil niches from Victoria Valley [51]. Their cosmopolitan distribution in terrestrial environments seems to be related to $\mathrm{pH}$ and soil moisture; in particular, the highest relative abundances were observed where $\mathrm{pH}$ is neutral and several studies in arid and semiarid habitats reported many Gemmatimonadetes phylotypes, suggesting a possible adaptation to drier soils like those found in the MDV [50]. A positive significant correlation between Gemmatimonadetes and candidate division WPS-2 suggests to deeply investigate their metabolisms and primary energy sources, also in the light of a recent study, where genes, supporting $\mathrm{CO}_{2}$ fixation through the Calvin-Benson-Bassham (CBB) cycle, were found in candidate division WPS-2, Actinobacteria and AD3 phyla in Antarctic desert soils [52]. Moreover, the role of temperature should be studied on the growth of candidate division WPS-2 phylum because these two phyla frequently occur in the same habitats with different abundances [44, 53]. Moreover, phototrophic members of candidate division WPS-2 seem to prefer cold, acidic and aerobic environments with access to sunlight [54]. Another interesting correlation is between Cyanobacteria and Planctomycetes. Cyanobacteria are commonly identified in Antarctic endolithic communities, and this phylum is commonly found in hypolithic and chasmoendolithic microbial communities [6, 49, 55, 56]. Cyanobacteria were abundant in two localities (FM and SP) only; their spatial distribution confirms previous studies in which Cyanobacteria abundances vary greatly even across Antarctic soils, mainly depending on water sources $[44,57]$. Although reads assigned to Planctomycetes were recovered even in rocks, this phylum is typically found in freshwater samples, marine sediments, cryoconite holes or associated with soft corals in Antarctica, suggesting a more specific adaptation to habitats where liquid, salty water is available [58-60]. However, in these peculiar rock niches, they may take advantages of the following situations that may favour their settlement and success: (i) the presence of Cyanobacteria, among which some taxa are aerobic nitrogen fixing and their metabolic activities could be the source of ammonium, used by some Planctomycetes anammox genera; (ii) the transient presence of liquid water due to freezing/ thawing of water in the undersides and the interstices of rocks; and (iii) the high salt concentration that may occur on rock surface due to the strong evaporation of water, resulting in salt efflorescence on rock surfaces [61]. Furthermore, Cai et al. suggested that the abundance of Planctomycetes phylum in cyanobacterial blooms could be related to the degradation of the sulphated polysaccharides produced by Cyanobacteria in the Chinese eutrophic Lake Taihu [62]. Another positive relationship showing strong co-occurrence patterns between Cyanobacteria and Planctomycetes was also found in eutrophic lakes in China [63].

Bacterial community correlations and different phyla distribution in sampling sites could be also explained considering the presence of lichens. Culturing approaches have revealed the presence of Actinobacteria and Proteobacteria as major phyla associated with Antarctic lichens [9, 12, 64]. A recent study, carried out through 454 pyrosequencing, added Acidobacteria and Bacteroidetes phyla to predominant bacterial phyla in Antarctic lichens [65]. Niederberger et al. [36] revealed that bacterial communities grouped in distinct clusters specific to arid and wet soils and both Acidobacteria and Deinococcus-Thermus phyla shared the higher abundances in the arid MDV soils with Bacteroidetes, Firmicutes and Gemmatimonadetes, contrary to Cyanobacteria, which preferred wetted soils. Although representatives of the phylum Deinococcus Thermus have been frequently isolated in Antarctic environmental samples $[9,66]$, in this study, a very few reads were assigned to this taxon; the significant positive correlation with Acidobacteria is worth to be investigated in the future considering the edaphic features of Siegfried Peak samples where the highest number of reads was retrieved for both these phyla.

This study evidenced that opposite sun exposure may influence bacterial assemblage of the cryptoendolithic lichen-dominated communities in terms of diversity and composition, and for the presence of marker species, even if to a lesser extent compared to fungi $[14,67]$. We also found, as previously reported, a high local diversification more pronounced along with longer distances $[2,14,68$, 69]. Apparently, the effect of geographic distances in these remote and inhospitable environments plays a determinant role in shaping biodiversity since the successful settlement of bacterial cells is extremely challenging and may be based on an incidental success as for the founder or bottleneck effects promoting the evolution of local populations. The evidence of positive correlations underlines the importance of strong cooperation to withstand the border conditions of the studied rocks, rather than competition. Although the biodiversity of prokaryotes in Dry Valleys' rocks is still far from being fully described, the study of an edaphic factor, such as solar exposure, adds an important contribution to 
the mosaic of microbial biodiversity of Antarctic cryptoendolithic communities.

Supplementary Information The online version contains supplementary material available at https://doi.org/10.1007/s00248-021-01769-w.

Acknowledgements L.S. and C.C. wish to thank the Italian National Program for Antarctic Researches (PNRA) for funding sampling campaigns and research activities in Italy in the frame of PNRA projects. The Italian Antarctic National Museum (MNA) is kindly acknowledged for financial support to the Mycological Section of the MNA and for providing rock samples used in this study and stored in the Culture Collection of Fungi From Extreme Environments (MNA-CCFEE), hosted at the University of Tuscia, Italy.

Author Contribution Not applicable for that section.

Funding Open access funding provided by Università degli Studi di Perugia within the CRUI-CARE Agreement. The research was supported by the Italian National Program for Antarctic Research (PNRA16_00194_A1).

Data Availability The data are available in European Nucleotide Archive (EMBL - EBI) under accession number PRJEB39480.

Code Availability Not applicable for that section.

\section{Declarations}

Ethics Approval Not applicable for that section.

Consent to Participate Not applicable for that section.

Consent for Publication If accepted, consent is given for publication.

Conflict of Interest The authors declare no conflict of interest.

Open Access This article is licensed under a Creative Commons Attribution 4.0 International License, which permits use, sharing, adaptation, distribution and reproduction in any medium or format, as long as you give appropriate credit to the original author(s) and the source, provide a link to the Creative Commons licence, and indicate if changes were made. The images or other third party material in this article are included in the article's Creative Commons licence, unless indicated otherwise in a credit line to the material. If material is not included in the article's Creative Commons licence and your intended use is not permitted by statutory regulation or exceeds the permitted use, you will need to obtain permission directly from the copyright holder. To view a copy of this licence, visit http://creativecommons.org/licenses/by/4.0/.

\section{References}

1. Bockheim JG (2002) Landform and soil development in the McMurdo Dry Valleys, Antarctica: a regional synthesis. Arc Antarct Alp Res 34:308-317

2. Feeser KL, Van Horn DJ, Buelow HN, Colman DR, McHugh TA, Okie JG et al (2018) Local and regional scale heterogeneity drive bacterial community diversity and composition in a Polar Desert. Front Microbiol 9:1928
3. Cary SC, McDonald IR, Barrett JE, Cowan DA (2010) On the rocks: the microbiology of Antarctic Dry Valley soils. Nat Rev Microbiol 8:129-138. https://doi.org/10.1038/nrmicro2281

4. Cowan DA, Khan N, Pointing SB, Cary SC (2010) Diverse hypolithic refuge communities in the McMurdo Dry Valleys. Antarct Sci 22:714-720

5. Coleine C, Stajich JE, Zucconi L, Onofri S, Pombubpa N, Egidi E, Franks A et al (2018) Antarctic cryptoendolithic fungal communities are highly adapted and dominated by Lecanoromycetes and Dothideomycetes. Front Microbiol 9:1392

6. Friedmann EI, McKay CP, Nienow JA (1987) The cryptoendolithic microbial environment in the Ross Desert of Antarctica: satellite-transmitted continuous nanoclimate data, 1984 to 1986 . Polar Biol 7(5):273-287

7. Selbmann L, Onofri S, Coleine C, Buzzini P, Canini F, Zucconi L (2017) Effect of environmental parameters on biodiversity of the fungal component in the lithic Antarctic communities. Extremophiles 21:1069-1080

8. Friedmann EI (1982) Endolithic microorganisms in the Antarctic cold desert. Science 215:1045-1053

9. de la Torre JR, Goebel BM, Friedmann E, Pace NR (2003) Microbial diversity of cryptoendolithic communities from the McMurdo Dry Valleys. Antarctica Appl Environ Microbiol 69:3858-3867

10. Karr EA, Sattley WM, Rice MR, Jung DO, Madigan MT, Achenbach LA (2005) Diversity and distribution of sulfate-reducing bacteria in permanently frozen Lake Fryxell, McMurdo Dry Valleys, Antarctica. Appl Environ Microbiol 71:6353-6359

11. Clocksin KM, Jung DO, Madigan MT (2007) Cold-active chemoorganotrophic bacteria from permanently ice-covered Lake Hoare, McMurdo Dry Valleys, Antarctica. Appl Environ Microbiol 73:3077-3083

12. Lee J, Cho J, Cho Y, Cho A, Woo J, Lee J et al (2019) The latitudinal gradient in rock-inhabiting bacterial community compositions in Victoria Land, Antarctica. Sci Tot Environ 657:731-738

13. Coleine C, Pombubpa N, Zucconi L, Onofri S, Stajich JE, Selbman L (2020) Endolithic fungal species markers for harshest conditions in the McMurdo Dry Valleys. Antarctica Life $10: 13$

14. Coleine C, Pombubpa N, Zucconi L, Onofri S, Turchetti B, Buzzini P et al (2020) Uncovered microbial diversity in Antarctic Cryptoendolithic communities sampling three representative locations of the Victoria Land. Microorganisms 8(6):942

15. Bradshaw MA (1981) Paleoenvironmental interpretations and systematics of Devonian trace fossils from the Taylor Group (lower Beacon Supergroup), Antarctica. NZ J Geol Geophys 24(5-6):615-652

16. Casnedi R, Di Giulio A (1999) Sedimentology of the section peak formation (Jurassic), Northern Victoria Land, Antarctica. Int Assoc Sedimentol 28:435-448

17. Marchant DR, Head JW (2007) Antarctic dry valleys: microclimate zonation, variable geomorphic processes, and implications for assessing climate change on Mars. Icarus 192:187-222

18. Friedmann EI, Weed R (1987) Microbial trace-fossil formation, biogenous, and abiotic weathering in the Antarctic cold desert. Science 236(4802):703-705

19. Deegenaars ML, Watson K (1998) Heat shock response in psychrophilic and psychrotrophic yeast from Antarctica. Extremophiles 2(1):41-50

20. Kalra YP (1995) Determination of $\mathrm{pH}$ of soils by different methods: collaborative study. J AOAC Int 78:310-324. https://doi.org/ 10.1093/jaoac/78.2.310

21. Takahashi S, Tomita J, Nishioka K, Hisada T, Nishijima M (2014) Development of a prokaryotic universal primer for simultaneous analysis of bacteria and archaea using next-generation sequencing. PLoS ONE 9(8):e105592 
22. Palmer JM, Jusino MA, Banik MT, Lindner DL (2018) Nonbiological synthetic spike-in controls and the AMPtk software pipeline improve mycobiome data. Peer J 6:e4925. https://doi.org/10. 7717/peerj.4925

23. Rognes T, Flouri T, Nichols B, Quince C, Mahé F (2016) VSEARCH: a versatile open source tool for metagenomics. Peer J 4:e2584. https://doi.org/10.7717/peerj.2584

24. Edgar RC (2010) Search and clustering orders of magnitude faster than BLAST. Bioinformatics 26:2460-2461

25. Chen H (2018) VennDiagram: generate high-resolution Venn and Euler plots. R package version 1(6):20

26. Larsson, J. (2020) eulerr: area-proportional Euler and Venn diagrams with ellipses. R package version 6.1.0, URL: https://cran.rproject.org/package=eulerr

27. Warnes GR, Bolker B, Bonebakker L, Gentleman R, Huber W, Liaw A et al (2020) gplots: various R programming tools for plotting data. R package version $3: 3$

28. Oksanen J, Blanchet FG, Friendly M, Kindt R, Legendre P, McGlinn D et al. (2019) Vegan: community ecology package. R Package Version 2.5-5

29. Segata N, Izard J, Waldron L, Gevers D, Miropolsky L, Garrett WS, Huttenhower C (2011) Metagenomic biomarker discovery and explanation. Genome Biol 12:R60

30. Harrell FE, Dupont MC. R Package Hmisc R Foundation for statistical computing, Vienna, Austria https://cran.rproject.org/web/ packages/Hmisc/Hmisc.pdf(2014)

31. Nienow JA, McKay CP, Friedmann EI (1988) The cryptoendolithic microbial environment in the Ross Desert of Antarctica: light in the photosynthetically active region. Microb ecol 16(3):271-289

32. Pudasaini S, Wilson J, Ji M, van Dorst J, Snape I, Palmer AS et al (2017) Microbial diversity of Browning Peninsula Eastern Antarctica revealed using molecular and cultivation methods. Front Microbiol 8:591

33. Crits-Christoph A, Robinson KC, Ma B, Ravel J, Wierzchos J, Ascaso C et al (2016) Phylogenetic and functional substrate specificity for endolithic microbial communities in hyper-arid environments. Front Microbiol 7:301

34. Karlov DS, Marie D, Sumbatyan DA, Chuvochina MS, Kulichevskaya IS, Alekhina IA, Bulat SA (2017) Microbial communities within the water column of freshwater Lake Radok, East Antarctica: predominant $16 \mathrm{~S}$ rDNA phylotypes and bacterial cultures. Polar Biol 40:823-836

35. Koo H, Mojib N, Hakim JA, Hawes J, Tanabe J, Andersen DT, Bej AK (2017) Microbial communities and their predicted metabolic functions in growth laminae of a unique large conical mat from Lake Untersee. East Antarctica Front Microbiol 8:1347

36. Niederberger TD, Sohm J, Gunderson TE, Parker AE, Tirindelli J, Capone DG et al (2015) Microbial community composition of transiently wetted Antarctic Dry Valley soils. Front Microbiol $6: 1-12$

37. Weisleitner K, Perras A, Moissl-Eichinger C, Andersen DT, Sattler B (2019) Source environments of the microbiome in perennially ice-covered Lake Untersee. Antarctica Front Microbiol 10:1019

38. Ghesheva V, Stackebrandt E, Vasileva-Tonkova E (2010) Biosurfactant production by halotolerant Rhodococcus fascians from Casey Station Wilkes Land, Antarctica. Curr Microbiol 61:112-117

39. Silva LJ, Souza DT, Genuario DB, Vargas Hoyos HA, Nobre Santos S, Rosa LH et al (2018) Rhodococcus psychrotolerans sp. nov., isolated from rhizosphere of Deschampsia antarctica. Antonie Van Leeuwenhoek 111:629-636

40. Majidzadeh M, Fatahi-Bafghi M (2018) Current taxonomy of Rhodococcus species and their role in infections. Eur J Clin Microbiol 37:2045-2062
41. Goordial J, Raymond-Bouchard I, Zolotarov Y, de Bethencourt L, Ronholm J, Shapiro N et al (2016) Cold adaptive traits revealed by comparative genomic analysis of the eurypsychrophile Rhodococcus sp. JG3 isolated from high elevation McMurdo Dry Valley permafrost Antarctica. FEMS Microbiol Ecol 92:fiv154

42. Ruberto LAM, Vazquez S, Lobalbo A, Mac Cormack WP (2005) Psychrotolerant hydrocarbon-degrading Rhodococcus strains isolated from polluted Antarctic soils. Antarct Sci 17(1):47-56

43. Gran-Scheuch A, Fuentes E, Bravo DM, Jiménez JC, Pérez-Donoso JM (2017) Isolation and characterization of phenanthrene degrading bacteria from diesel fuel-contaminated antarctic soils. Front Microbiol 8:1634

44. Kim M, Cho A, Lim HS, Hong SG, Kim JH, Lee J et al (2015) Highly heterogeneous soil bacterial communities around Terra Nova Bay of Northern Victoria Land. Antarctica PloS One 10(3):e0119966

45. Tebo BM, Davis RE, Anitori RP, Connell LB, Schiffman P, Staudigel H (2015) Microbial communities in dark oligotrophic volcanic ice cave ecosystems of Mt. Erebus. Antarctica Front Microbiol 6:1-14

46. Yabe S, Sakai Y, Abe K, Yokota A (2017) Diversity of Ktedonobacteria with actinomycetes-like morphology in terrestrial environments. Microbes Environ 32:61-70

47. Esposito A, Borruso L, Rattray JE, Brusetti L, Ahmed E (2019) Taxonomic and functional insights into rock varnish microbiome using shotgun metagenomics. FEMS Microbiol Ecol 95(12):fiz180. https://doi.org/10.1093/femsec/fiz180

48. Yabe S, Sakai Y, Yokota A (2016) Thermosporothrix narukonensis sp. nov., belonging to the class Ktedonobacteria, isolated from fallen leaves on geothermal soil, and emended description of the genus Thermosporothrix. Int J Syst Evol Microbiol 66:2152-2157

49. Yung CCM, Chan Y, Lacap DC, Pérez-Ortega S, de los RiosMurillo A, Lee CK et al (2014) Characterization of Chasmoendolithic community in Miers Valley, McMurdo Dry Valleys Antarctica. Microb Ecol 68:351-359

50. DeBruyn JM, Nixon LT, Fawaz MN, Johnson AM, Radosevich $M$ (2011) Global biogeography and quantitative seasonal dynamics of Gemmatimonadetes in soil. Appl Environ Microbiol 77:6295-6300

51. Van Goethem MW, Makhalanyane TP, Valverde A, Cary SC, Cowan DC (2016) Characterization of bacterial communities in lithobionts and soil niches from Victoria Valley, Antarctica. FEMS Microbiol Ecol 92:fiw051

52. Ji M, Greening C, Vanwonterghem I, Carere CR, Bay SK, Steen JA, Montgomery K et al (2017) Atmospheric trace gases support primary production in Antarctic desert surface soil. Nature 552:400-403

53. Ji M, van Dorst J, Bissett A, Brown MV, Palmer AS, Snape I, Siciliano S, Ferrari BC (2016) Microbial diversity at Mitchell Peninsula, Eastern Antarctica: a potential biodiversity "hotspot". Polar Biology 39:237-249

54. Ward LM, Cardona T, Holland-Moritz H (2019) Evolutionary implications of anoxygenic phototrophy in the bacterial phylum Candidatus Eremiobacterota (WPS-2). Front Microbiol 10:1658

55. Chan Y, Lacap DC, Lau MCY, Ha KY, Warren-Rhodes KA, Cockell CS et al (2012) Hypolithic microbial communities: between a rock and a hard place. Environ Microbiol 14:2272-2282

56. Makhalanyane T, Valverde A, Birkeland N, Cary SC, Tuffin IM, Cowan DA (2013) Evidence for successional development in Antarctic hypolithic bacterial communities. ISME J 7:2080-2090

57. Lambrechts S, Willems A, Tahon G (2019) Uncovering the uncultivated majority in Antarctic soils: toward a synergistic approach. Front Microbiol 10:242 
58. Christner BC, Kvitko BH, Reeve JN (2003) Molecular identification of bacteria and Eukarya inhabiting an Antarctic cryoconite hole. Extremophiles 7:177-183

59. Webster NS, Bourne D (2007) Bacterial community structure associated with the Antarctic soft coral, Alcyonium antarcticum. FEMS Microbiol Ecol 59:81-94

60. Lee YM, Kim EH, Lee HK, Hong SG (2014) Biodiversity and physiological characteristics of Antarctic and Arctic lichensassociated bacteria. World J Microbiol Biotechnol 30:2711-2721

61. Bisson KM, Welch KA, Welch SA, Sheets JM, Lyons WB, Levy JS, Fountain AG (2015) Patterns and processes of salt efflorescences in the McMurdo region, Antarctica. Arct Antarct Alp Res 47(3):407-425

62. Cai H, Yan Z, Wang A, Krumholz LR, Jiang H (2013) Analysis of the attached microbial community on mucilaginous cyanobacterial aggregates in the eutrophic Lake Taihu reveals the importance of Planctomycetes. Microb Ecol 66:73-83

63. Zhao DY, Shen F, Zeng J, Huang R, Yu ZB, Wu QL (2016) Network analysis reveals seasonal variation of co-occurrence correlations between Cyanobacteria and other bacterioplankton. Sci Total Environ 573:817-825
64. Selbmann L, Zucconi L, Ruisi S, Grube M, Cardinale M, Onofri S (2010) Culturable bacteria associated with Antarctic lichens: affiliation and psychrotolerance. Polar Biol 33:71-83

65. Park CH, Kim KM, Kim O, Jeong G, Hong SG (2016) Bacterial communities in Antarctic lichens. Antarct Sci. https://doi.org/10. 1017/S0954102016000286

66. Siebert J, Hirsch P (1988) Characterization of 15 selected coccal bacteria isolated from Antarctic rock and soil samples from the McMurdo-Dry Valleys (South-Victoria Land). Polar Biol 9:37-44

67. Coleine C, Zucconi L, Onofri S, Pombubpa N, Stajich JE (2018) Selbmann L (2018) Sun exposure shapes functional grouping of fungi in cryptoendolithic antarctic communities. Life 8(2):19

68. Archer SD, de los Ríos A, Lee KC, Niederberger TS, Cary SC, Coyne KJ et al (2017) Endolithic microbial diversity in sandstone and granite from the McMurdo Dry Valleys, Antarctica. Polar Biol 40:997-1006

69. Coleine C, Stajich JE, Pombubpa N, Zucconi L, Onofri S, Selbman L (2020) Sampling strategies to assess microbial diversity of Antarctic cryptoendolithic communities. Polar Biol 43:225-235 